\title{
Movimientos sociales y acción colectiva ${ }^{1}$ Un crisol de experiencias en el noroccidente mexicano
}

DOI: $10.46932 / \mathrm{sfjdv2n1-073}$

Received in: November 1st, 2020

Accepted in: December 30th, 2020

\author{
José Salvador Zepeda López \\ Universidad Autónoma de Nayarit \\ México \\ E-mail: josezep09@yahoo.com.mx
}

Enedina Heredia Quevedo

Universidad Autónoma de Nayarit, México

E-mail: enedinahq@hotmail.com

\section{Olimpia Jiménez López}

Universidad Autónoma de Nayarit, México

E-mail: oj128@hotmail.com

\section{RESUMEN}

A partir de los años sesenta del siglo XX, en algunas regiones de México se van decantando distintos procesos sociopolíticos que caminan al margen de los cauces institucionales y van trazando líneas de acción más allá de la dinámica partidista y electoral. Motivados, en primera instancia, por un conjunto de demandas económicas, con el paso del tiempo y la falta de soluciones, organizaciones de distinto nivel, se van transformando, para llegar, en la década de los setenta y ochenta, a la conformación de grandes frentes populares de carácter sectorial y territorial. En esos procesos se han perfilado demandas y escenarios de confrontación -con distintas expresiones e intensidades- y en ello se ha dado la irrupción de una variedad de sujetos colectivos: campesinos, organizaciones de comuneros, sindicalizados, colonos, usuarios de servicios, vendedores ambulantes, invariablemente ligados a importantes núcleos políticos estudiantiles, entre universitarios y normalistas, dando lugar a cruciales manifestaciones en distintas regiones del país. Así, veremos la trayectoria de los distintos movimientos sociales en lo que identificamos como la porción noroccidental ${ }^{2}$ del país, enfatizando sobre el estado de Nayarit.

Palabras clave: Movimientos sociales/ Universidades/Acción Colectiva

\footnotetext{
${ }^{1}$ La presente es una versión ampliada de la ponencia presentada bajo el mismo título, en el XXXI Congreso de la Asociación Latinoamericana de Sociología (ALAS), celebrado en Montevideo, Uruguay, del 3 al 8 de diciembre de 2017.

${ }^{2}$ La porción noroccidental, para los fines de este trabajo, se ha considerado al conjunto de estados situados en la vertiente del pacífico hacia el norte, entre las que se encuentran Baja California, Baja California Sur, Sonora, Sinaloa, Nayarit, Jalisco, Colima y Michoacán.
} 


\section{LOS MOVIMIENTOS SOCIALES Y LA ACCIÓN COLECTIVA, APROXIMACIÓN CONCEPTUAL}

Existe un cúmulo de experiencias contadas a través de distintas obras y un amplio listado de autores en torno a los movimientos sociales. Entre los clásicos (Tilly y Wood, 2009; Touraine, 1982 y 1986), los que observan desde realidades concretas (León y Marván, 1989), desde ámbitos específicos como la ciudad (Castells, 1983a y1983b; Borja, 1974 y 1981); o la observación desde la dinámica conflictiva, como ocurre con el Movimiento Urbano Popular (Navarro, 1983; Moctezuma y Navarro, 1984; Perló y Schteingart, 1984; Ramírez, 1984) o la cuestión simbólica (Galindo, 1987); o bien desde la perspectiva de la sociedad civil (Núñez, 1990). La sociedad en movimiento, organizada y sus disputas por el espacio público y el afán de ser parte de la agenda y el poder como aspiración suprema, ha sido observada desde distintos ángulos. En nuestro trabajo recuperamos el aporte de Touraine (1982, 1986), quien a nuestro juicio aporta elementos clave para entender a la sociedad en perspectiva amplia y la dinámica conflictiva en la disputa por el poder y la transformación.

Al tratar de caracterizar al movimiento ecologista francés de 1977 a 1979, Touraine se refiere a los movimientos sociales como "una acción colectiva organizada, entablada contra un adversario social, y por la gestión de los medios a través de los cuales una sociedad actúa sobre sí misma y sobre sus relaciones con su entorno" (Touraine, 1982: 690).

En otro momento (1986) presenta una definición más acabada e introduce nuevos datos: habla de la existencia de "tres tipos de conflictos que tienden a modificar uno o varios aspectos importantes de la organización social y cultural". Con distintos niveles de organicidad", se llegan a expresar tanto "las conductas colectivas" como "las luchas" y "los movimientos sociales".

Las conductas colectivas son acciones conflictivas que pueden entenderse como un esfuerzo de defensa, reconstrucción o adaptación de un elemento enfermo del sistema social. Puede ser un valor, una norma, una relación de autoridad o de la sociedad como tal. En cuanto a "las luchas", se relacionan con la existencia de fuerzas sociales y políticas que se erigen en factores de cambio frente a situaciones dadas (carencia de vivienda, bajos salarios, irrespeto a precios de garantía para los productos del campo), es decir, no va más allá de algunas reivindicaciones, la mayoría de las veces de tipo económico.

Aunque en el marco de la lucha de clases, el movimiento social como expresión propia de ésta, no se le separa; la clase puede estar definida como una situación, en tanto el movimiento social sería la clase de sujeto, a partir de determinadas orientaciones culturales que conllevan a formas de organización social congruentes con normas culturales generales y relaciones de dominación social.

\footnotetext{
${ }^{3}$ Entiéndase ésta como la expresión de un conflicto a través de un órgano representativo que se mueve a partir de ciertos lineamientos que surgen de la participación consciente de la base en la formulación de un proyecto.
} 
De esa manera, para definir los movimientos sociales, tenemos que ubicarnos en tres planos, que no por ser diferentes deben verse en forma separada.

1.- Plano cultural.- Supone el conocimiento exhaustivo de esa situación de clase y conciencia plena, la identificación con ciertos símbolos.

2.- Plano social.- Parte del reconocimiento de una determinada situación de tipo clasista, es decir, de una posición frente a lo que es la distribución del ingreso, es decir, lo objetivo.

3.- Plano político.- Está referido a la identificación plena de un enemigo común en el marco de una lucha en la que se establecen ciertas relaciones de dominación, de las cuales se tienen una idea clara y se tiene, en contrapartida, un proyecto alternativo.

Así, para que un movimiento pueda considerarse como tal, tendría que partir de una condición socioeconómica de los actores, la cual se haría consciente, además de incorporar nuevos valores en relación con el nivel político, traducido en un proyecto alternativo. No podrá existir sin una cierta conciencia de sí mismo y no necesariamente puede organizarse y pensarse directamente sobre un plan político.

Cabe entonces definirlo como "las manifestaciones y las expresiones sociales de grandes conglomerados, tendientes a apoyar o cuestionar el estado de cosas específico, el sistema de relaciones vigente en determinada formación económico-social” (Mejía y Sarmiento, 1987:14). Ello engloba expresiones del campo como de la ciudad. Sectoriales: urbanos, campesinos, sindicales; culturales: género, juveniles, ambientales, derechos humanos.

Los movimientos sociales entran en decadencia, o al menos aquellos que como el movimiento urbano popular (MUP), el movimiento campesino o el movimiento obrero, autodefinidos en conjunto como "movimientos populares" en plural o en singular "movimiento popular" como parte de todo un procesos de acumulación de fuerzas en vía de la transformación sociopolítica del país confrontados con el modelo de dominación como "movimientos independientes"; respecto de los cuales señala Sergio Tamayo (2009), "su perspectiva se construyó combinando tres aspectos: las causas objetivas de la situación social, las formas de lucha y organización del movimiento, y la confrontación con el Estado, al que se definía como clasista y represor" (p. 97). En eso se acuñó una tradición, que en algunos casos se mantiene, profundiza y a la vez se inserta en la nueva realidad sociopolítica que se abre un amplio horizonte en lo electoral. El movimiento pasa también, como este mismo autor lo plantea, por la construcción de espacios de convergencia en que los distintos grupos sociales intercambiaron experiencias en cuanto a formas de organización y lucha que incluían estilos semejantes de establecer reuniones, formar comisiones, elegir representaciones políticas y sociales, interpretar la democracia directa, organizar 
asambleas, decidir por mayoría, aceptar o no la disidencia en el interior de las organizaciones, el derecho de formar fracciones y facciones políticas minoritarias, construir asociaciones de carácter legal (Ibíd.: 97).

Los años ochenta, en su parte final, y la llegada de los noventa, vieron florecer distintas experiencias en el ámbito de los movimientos sociales, que construyeron formas propias y muy eficaces para la acción con resultados diversos, la dinámica electoral trajo nuevas cosas y en ello fueron pocos los que sobrevivieron, la mayoría sucumbieron en el maremágnum de la vida electoral en todos los niveles.

\section{APROXIMACIÓN A LA REGIÓN DE OBSERVACIÓN}

En el ejercicio de identificación de nuestra región de estudio, suscribimos la idea de Van Young (1992), de que la región en si no existe y se constituye en una hipótesis, sujeta a ser probada, adoptando las características correspondientes a la aproximación o visión disciplinaria con que se asuma por parte del observador (el investigador) y la perspectiva en que se éste se ubique. Es un concepto elástico y pluriforme; o bien, como lo dice Link (1985), es flexible y capaz de proporcionar un marco global susceptible de utilizar, por lo que se construye en función de las disciplinas que lo utilizan y de región geográfica, económica, cultural, política, entre otras denominaciones: para cuya definición contribuyen una serie de indicadores (vocación natural, tipos de suelo más comunes, formas de especificación productiva, tradiciones, lenguas, etc.). Para el caso en que nos situamos hay tres elementos a tomar en cuenta: el geográfico, que se ve favorecido por las comunicaciones, el paisajístico, ligado al aspecto ecológico y el sociocultural, asociado a la dinámica de la sociedad en su devenir histórico con referencia a los distintos planos. En todo ello lo regional aparece como un recurso de aproximación a la realidad con fines analíticos, como veremos a continuación.

En otros términos, la región en sí reúne algunas características como definitivas:

a) tradicionalmente se le ha concebido como un espacio geográfico más grande que una localidad pero más pequeño que un Estado-nación (Van Young, ibíd.);

b) es un conjunto espacial relativamente homogéneo y dotado de personalidad propia ${ }^{4}$;

c) sus límites pueden cambiar con el tiempo, en la medida que se le adhieren áreas nuevas o se fragmentan y reagrupan algunas, las antiguas y tradicionales.

\footnotetext{
${ }^{4}$ Terry A. Link (1985), "Sistemas de producción y región”, en Alcántara Ferrer, Sergio y Enrique Sánchez Ruiz (Comps.), Desarrollo rural en Jalisco: Contradicciones y perspectivas. El Colegio de Jalisco/CONACYT, Guadalajara, Jal. México, p. 159.
} 
Por otra parte, a nivel conceptual, se visualiza como algo elástico, producto de la dinámica con que operan los cambios en la conformación del territorio y la forma que adopta su relación con la sociedad, que va diseñando dentro de éste sus distintos espacios de interacción. Viene a ser producto de un proceso social en el que cada uno de los actores, en interacción constante, le da contenido.

Así, hablar de la franja noroccidental del país parte, en primera instancia, de las condiciones geográficas, asociadas al devenir histórico de esta porción del territorio, que ha sido articulado por las vías de comunicación con la frontera norte del país, y, por otro lado, con fuertes ligas con el centrooccidente y su principal referente, Guadalajara, como ciudad eje. Es decir, el eje noroccidental no es un elemento aislado y sí en cambio se torna en algo sumamente relevante, más si le vemos desde la perspectiva sociopolítica y cultural articulada desde la geografía y las vías de comunicación.

En la propuesta de esta región, se reconoce en ella un elemento articulador inicial -las vías de comunicación terrestre-, que le han unido prácticamente desde el siglo XVII, afirmándose en el XX a través del trazo de la vía del ferrocarril, durante las dos primeras décadas y la carretera federal no. 15 entre los años cuarenta y cincuenta, justo en la fase final de la segunda guerra mundial. Momento clave en los desplazamientos de población desde el occidente y el flujo de mercancías, que desde este punto transitaban hacia la frontera sur de los Estados Unidos, que se convierte en el principal socio comercial de México, derivado del conflicto bélico. Es decir, la propuesta de región se plantea en el entendido de que ésta conforma una unidad territorial dada a través de las vías de comunicación, terrestres en mayor medida, una historia sociodemográfica y política más o menos homogénea, dada a través de los flujos de población en distintos sentidos; es decir, de sur a norte tomando como sitios de paso y alternativos para vivir, a los núcleos de población del noroeste y viceversa, fundamentalmente, por la atracción que ejercen Guadalajara y algunas localidades nayaritas, michoacanas y de Colima. Del otro lado, por las dimensiones del territorio en cuestión, es de reconocerse que su composición y dinámica sociodemográfica no son uniformes, de ahí que también estemos hablando de una región diferenciada en su interior, más si sumamos a la reflexión el elemento político electoral, que encierra un conjunto de experiencias diversas que le dan al mapa un amplio colorido de expresiones.

\section{UNIVERSIDAD Y ACCIÓN SOCIAL EN LA REGIÓN, EL RASTRO DE LA GUERRILLA}

Desde mediados del siglo pasado, en forma por demás prematura, el modelo de dominación instaurado a raíz del movimiento armado de 1910 y las subsecuentes acciones que motivaron la conformación de un nuevo pacto nacional que dio lugar a su vez a lo que se reconoce como el Estado Posrevolucionario. Empero, el parteaguas sería al final de los sesenta y principios de los setenta, con los actos represivos del 2 de octubre de 1968 y en forma posterior, el 10 de junio de 1971. Con estos se 
definen para los actores involucrados, entre estudiantes y activistas sociales, distintos derroteros: unos se repliegan, otros van a exilio al extranjero, otros pasan a la clandestinidad, dando paso a nuevas formas de lucha, incorporándose a la lucha social, mantienen estrechos vínculos con los espacios educativos, viene también la guerrilla y viene por otra parte la conformación de proyectos orgánicos de masas que se erigen en la contraparte y alternativa frente a los sectores priistas, en los que convergían los distintos movimientos populares, o movimientos sociales independientes.

En términos generales, la presencia en la acción, de parte de los estudiantes, tiene sus referentes en México en los movimientos populares de los años cincuenta y sesenta, particularmente el caso del 68 que tuvo grandes repercusiones, inclusive, a nivel internacional. Este a su vez estuvo precedido por una serie de movilizaciones que le acercan a un movimiento de dimensión nacional. Gilberto Guevara Niebla (1988), describe el panorama previo al movimiento estudiantil popular de 1968. En su texto hace referencia a que en esa época "tuvo lugar el único movimiento de carácter nacional que ocurrió en el período previo a 1968: la huelga nacional de apoyo a los estudiantes de la Escuela Superior de Agricultura Hermanos Escobar de Ciudad Juárez, Chihuahua, que protestaban contra el régimen de abusos impuesto por los propietarios de esa institución privada y pedían la ‘federalización’ de la escuela.” (P.34). En el mismo lo califica como uno de los más importantes, e impresionantes, movimientos de carácter local al concitar la afluencia de solidaridades y hermanamientos con distintos contingentes estudiantiles del país. En un lapso que transcurre entre los meses de mayo y junio de 1968, se incorporan al movimiento en solidaridad, según el mismo Guevara, en lo que la huelga nacional alcanzó a incorporar a 70,000 estudiantes de todo el país. Entre éstos figuraban los estudiantes del Instituto Politécnico Nacional (IPN) en donde, después de 11 años de paz interior, se declaró una huelga general. Junto a estos se incorporaron contingentes de la Escuela Nacional de Agricultura de Chapingo, la mayoría de las escuelas y facultades de agricultura del país, las escuelas normales rurales a nivel nacional (entre las que figuraban Ayotzinapa, Guerrero, Atequiza, Jalisco y Tiripetio, Michoacán), la Escuela Normal Superior de México y distintos contingentes de universidades públicas del país. Cabe destacar que la lucha a la que se hace referencia "se organizó a través de un Consejo Nacional de Huelga y Solidaridad que sería el antecedente inmediato del CNH de 1968. El vigor del movimiento impidió que interviniera el ejército, con lo cual ya había amenazado la autoridad" (Ibíd. p. 34).

Respecto al movimiento estudiantil del 68, cabe señalar que este surge planteando diferencias con relación a lo que había venido ocurriendo de manera tradicional. El mismo Guevara Niebla establece que hay un conjunto de características que le hacen diferente del movimiento estudiantil anterior, enumerándolas de la siguiente manera:

"1. El carácter de masas de las luchas estudiantiles. 
2. El carácter político independiente de la dirección estudiantil (en relación a las fuerzas oficiales).

3. La ruptura con las organizaciones históricas del estudiantado.

4. La unidad estudiantil; la superación de la vieja escisión entre la tradición liberal y la popular, y

5. El carácter político-democrático de las luchas: en unos casos se orientaron a la democratización interna de las universidades, pero en la mayoría de ellos, las luchas estudiantiles involucraron un principio de crítica -a veces implícito- contra el orden político, antidemocrático y autoritario que privaba en la sociedad mexicana.

6. Finalmente, en las luchas locales más fuertes -Michoacán, 1963 y 1966; Puebla, 1961-1964; Guerrero, 1960, Sonora, 1967- el movimiento estudiantil se vinculó a sectores populares, y

7. La ausencia de organizaciones permanentes." (P. 35).

Este es el contexto que rodea a las Universidades en las décadas de los sesenta y setenta, que resulta crucial en el devenir de la relación Universidad-Estado y Universidad-Sociedad. El paso por las aulas universitarias permitió la formación de estudiantes que pronto adquirieron el papel de intermediarios entre los pobladores de su entorno, sus demandas y las instancias/autoridades responsables de atender. El cuadro siguiente delinea la manifestación de la historia política electoral y el tipo de movimiento social existentes en la región de estudio.

Es una época en que floreció la lucha social y política y en una fase superior emergieron los movimientos armados, abrazados por parte de estudiantes, profesores, obreros y campesinos en distintos puntos de la geografía nacional, sobre todo en la segunda mitad de los años setenta, teniendo como su principal referente a la Liga Comunista 23 de Septiembre que, no obstante lo golpeado que estaba para entonces, a través de una intensa campaña de agitación y propaganda se dio lugar al surgimiento de brigadas en Monterrey, Chihuaha, Durango, Estado de México, Puebla, Guerrero, Veracruz, Chiapas, Oaxaca y la mayor parte de la franja noroccidental, parte de nuestro núcleo de interés, principalmente Baja Caifornia Norte, Sonora, Sinaloa, Nayarit, Jalisco y Michoacán, de acuerdo con Castellanos (2007).

Demandas sociales, régimen político, lucha social, organización y movimientos sociales son aspectos que tienen una liga muy fuerte con el ámbito educativo. Entre los estudiantes, el magisterio, las comunidades rurales y las masas urbanas se han configurado esquemas de relación y convivencia a lo largo de la historia, como ocurre en la región de estudio.

Sociedad y política en el noroccidente de México, últimos 50 años

\begin{tabular}{|l|l|l|l|l|l|l|l|l|}
\hline $\begin{array}{l}\text { Condición } \\
\text { socio } \\
\text { política/Est } \\
\text { ado }\end{array}$ & $\begin{array}{l}\text { Baja } \\
\text { Californi } \\
\text { a }\end{array}$ & $\begin{array}{l}\text { Baja } \\
\text { California } \\
\text { Sur }\end{array}$ & Colima & Jalisco & $\begin{array}{l}\text { Michoacá } \\
\text { n }\end{array}$ & Nayarit & Sinaloa & Sonora \\
\hline $\begin{array}{l}\text { Historial } \\
\text { político } \\
\text { electoral }\end{array}$ & $\begin{array}{l}\text { Bipartidis } \\
\text { mo } \\
\text { alternante }\end{array}$ & $\begin{array}{l}\text { Tripartidis } \\
\text { mo } \\
\text { Alternante }\end{array}$ & $\begin{array}{l}\text { Priismo } \\
\text { prolonga } \\
\text { do }\end{array}$ & $\begin{array}{l}\text { Bipartidis } \\
\text { mo } \\
\text { alternante }\end{array}$ & $\begin{array}{l}\text { Bipartidis } \\
\text { mo } \\
\text { alternante }\end{array}$ & $\begin{array}{l}\text { Tripartidis } \\
\text { mo } \\
\text { alternante }\end{array}$ & $\begin{array}{l}\text { Bipartidis } \\
\text { mo } \\
\text { alternante }\end{array}$ & $\begin{array}{l}\text { Bipartidis } \\
\text { mo } \\
\text { Alternante }\end{array}$ \\
\hline
\end{tabular}




\begin{tabular}{|c|c|c|c|c|c|c|c|c|}
\hline $\begin{array}{l}\text { Movimiento } \\
\text { s sociales }\end{array}$ & $\begin{array}{l}\text { MUP } \\
\text { Sindical } \\
\text { Estudianti } \\
\text { 1/ } \\
\text { Universita } \\
\text { rio } \\
\text { Guerrilla }\end{array}$ & $\begin{array}{l}\text { Jornaleros } \\
\text { agrícolas } \\
\text { Ambientali } \\
\text { stas }\end{array}$ & $\begin{array}{l}\text { Estudiant } \\
\text { il } \\
\text { Ambienta } \\
1\end{array}$ & $\begin{array}{l}\text { MUP } \\
\text { Sindical/ } \\
\text { Magisterial } \\
\text { Estudiantil } \\
\text { / } \\
\text { universitari } \\
\text { o } \\
\text { Estudiantil } \\
\text { / } \\
\text { normalista } \\
\text { Ambientali } \\
\text { sta } \\
\text { Guerrilla }\end{array}$ & $\begin{array}{l}\text { MUP } \\
\text { Sindical/ } \\
\text { Magisterial } \\
\text { Campesino } \\
\text { Comunal } \\
\text { Estudiantil } \\
\text { / } \\
\text { universitari } \\
\text { o } \\
\text { Estudiantil } \\
\text { / } \\
\text { normalista } \\
\text { Ambientali } \\
\text { sta } \\
\text { Autodefen } \\
\text { sas } \\
\text { Étnico } \\
\text { Guerrilla }\end{array}$ & $\begin{array}{l}\text { MUP } \\
\text { Campesin } \\
\text { o } \\
\text { Sindical } \\
\text { Estudiantil } \\
\text { / } \\
\text { universitar } \\
\text { io } \\
\text { Guerrilla }\end{array}$ & $\begin{array}{l}\text { MUP } \\
\text { Campesin } \\
\text { o } \\
\text { Estudianti } \\
\text { 1/ } \\
\text { Universita } \\
\text { rio } \\
\text { Guerrilla }\end{array}$ & $\begin{array}{l}\text { Campesin } \\
\text { o } \\
\text { Estudianti } \\
1 / \\
\text { universita } \\
\text { rio } \\
\text { Guerrilla }\end{array}$ \\
\hline $\begin{array}{l}\text { Institución y } \\
\text { / o } \\
\text { organización }\end{array}$ & $\begin{array}{l}\text { Universid } \\
\text { ad } \\
\text { Autónoma } \\
\text { de Baja } \\
\text { California }\end{array}$ & $\begin{array}{l}\text { Universida } \\
\text { d } \\
\text { Autónoma } \\
\text { de Baja } \\
\text { California } \\
\text { Sur }\end{array}$ & $\begin{array}{l}\text { Universid } \\
\text { ad de } \\
\text { Colima }\end{array}$ & $\begin{array}{l}\text { Universida } \\
\text { d de } \\
\text { Guadalajar } \\
\text { a }\end{array}$ & $\begin{array}{l}\text { Universida } \\
\text { d } \\
\text { Michoacan } \\
\text { a de San } \\
\text { Nicolás de } \\
\text { Hidalgo }\end{array}$ & $\begin{array}{l}\text { Universida } \\
\text { d } \\
\text { Autónoma } \\
\text { de Nayarit }\end{array}$ & $\begin{array}{l}\text { Universid } \\
\text { ad } \\
\text { Autónoma } \\
\text { de Sinaloa } \\
\text { (UAS) }\end{array}$ & $\begin{array}{l}\text { Universid } \\
\text { ad de } \\
\text { Sonora }\end{array}$ \\
\hline
\end{tabular}

Fuente: Elaboración propia con base en la consulta de distintos documentos locales y crónicas relativas a la época

Con base en lo anterior, nos proponemos un breve recorrido por los distintos casos incorporados al presente documento en el que se trata de identificar y mostrar en forma sucinta las vinculaciones existentes entre la universidad como ente público formador de conciencias y potenciador en forma indirecta de la lucha social popular en el contexto regional y local.

Un caso por demás interesante en la región es el de la Universidad Autónoma de Sinaloa (UAS). La UAS estuvo inmersa en una situación de fuertes vínculos con la lucha social y política en el entorno estatal. Las distintas coyunturas vividas a nivel general y local marcan de manera importante el derrotero que seguiría la institución. Desde los años dorados del priismo, las luchas por la autonomía y el decantamiento de una estrecha relación de los universitarios con la sociedad hasta el momento álgido de la guerrilla, la UAS vivió una fuerte convulsión. Se encuentra, por ejemplo, lo que en su momento representó la Federación de Estudiantes Universitarios Sinaloenses (FEUS), grupo denominado "Los Enfermos", que dada su posición política radical se incorporó a la Liga Comunista 23 de Septiembre. Al mismo tiempo, el caso Sonora llama la atención por lo prematuro de sus manifestaciones en la lucha social, destaca por un movimiento estudiantil que antecede, incluso a las grandes experiencias a nivel nacional, al propio movimiento estudiantil popular de 1968; un movimiento con importantes anclajes sociales, principalmente entre los núcleos campesinos, un estudiantado inmerso en una lógica de transformación constante y de distanciamiento ante la institucionalidad.

La periodista y escritora Laura Castellanos (2007), en un interesante y muy completo texto sobre el tema, al abordar las cuestiones relacionadas con el origen de la lucha armada en México, con base en 
la tesis de la "Universidad fábrica" 5 , la resume de la siguiente manera: "la educación se ha masificado en la sociedad capitalista, lo que convertía a las universidades en fábricas de reproducción cultural y económica. El estudiantado era, pues, el proletario. Así, la responsabilidad histórica que la tesis marxista-leninista le daba a los obreros explotados y despojados de los medios de producción (el proletariado) pasaba ahora al estudiantado, que ya no era solamente su aliado, sino su propia vanguardia revolucionaria” (P. 206). Lo anterior marco en buena medida, el derrotero que seguirían los movimientos estudiantiles y estarían definiendo sus vínculos con la realidad social y al mismo tiempo les darían el sustento para escalar en la lucha revolucionaria.

De la misma manera, se destaca, para el caso de la Universidad de Sonora, "diversas corrientes tenían presión sobre la universidad. Una era la denominada "universidad democrática, crítica y popular", promovida por el Partido Comunista Mexicano y puesta en práctica en lugares como Sinaloa, Puebla, Monterrey y Guerrero, y en forma posterior en Nayarit, con algunos visos de acción que fluctúan entre la radicalidad del movimiento armado y los movimientos sociales, que poco a poco permitirían, desde la universidad, acercarse a distintos sectores sociales, tanto en el campo como en la ciudad. Otra era la tesis de la "universidad roja", planteada por los trotskistas, y la tercera, la de la "universidad fábrica", por los ultraizquierdistas. Verdugo (2004), de manera sintética pero clara, explica en qué consiste cada una de ellas y cómo los simpatizantes de las diversas corrientes debatían entre sí.

De noviembre de 1973 a principios de 1974 se desató la represión contra el movimiento. Decenas de maestros y estudiantes fueron expulsados, otros detenidos y otros más desterrados; durante esos meses se desató una cacería de brujas, de modo que era un verdadero riesgo traer cualquier libro que pareciera marxista. Los activistas que no salieron del estado pasaron a la clandestinidad engrosando las filas de las diversas organizaciones políticas que participaban en el seno del movimiento estudiantil, planteándose todas ellas la conformación de un partido de la clase obrera que luchara por el socialismo. Los más desesperados decidieron pasar a la acción directa "contra las fuerzas represivas del Estado burgués", integrándose a organizaciones de carácter guerrillero como la "Liga Comunista 23 de Septiembre", los cuales durante 1974 protagonizaron varios enfrentamientos en donde hubo muertos tanto de policías como de estudiantes (Sánchez, 2006).

Por otra parte, de acuerdo con Oikion, "El movimiento guerrillero desencadenado en Guadalajara tuvo su origen en la radicalización política del estudiantado universitario agrupado en el Frente Estudiantil Revolucionario (FER), integrado en 1970 con contingentes de los barrios populares de la ciudad y con

\footnotetext{
${ }^{5}$ Estas tesis serían elaboradas por parte de Ignacio Salas Obregón, líder de los Procesos (cristianos radicales de Monterrey) e Ignacio Olivares elaboran la tesis de la Universidad Fábrica para legitimar el liderazgo estudiantil guerrillero, según se menciona en el portal "Memoria política de México"

[http://www.memoriapoliticademexico.org/Efemerides/3/15031973.html]
} 
jóvenes de la Juventud Comunista y de la Liga Comunista Espartaco (LCE), principalmente. En su afán por abrir espacios democráticos dentro de la Universidad de Guadalajara, el FER se opuso hasta con las armas en la mano a la Federación de Estudiantes de Guadalajara (FEG), organización gangsteril que representaba el control del gobierno priista dentro de la Universidad entre los años cincuenta y principios de los setenta. La radicalidad del FER abrió algunos cauces, por los cuales transitó el entusiasmo juvenil con el ánimo de integrarse a la acción guerrillera en Guadalajara. Un primer grupo, el más numeroso, se aglutinó en torno a la Liga Comunista 23 de Septiembre (LC23S). El segundo agrupamiento constituyó la Unión del Pueblo (UP). La tercera organización fueron las Fuerzas Revolucionarias Armadas del Pueblo (FRAP)" (p. 258), lo que nos da una idea más o menos amplia de la magnitud de los conflictos, la articulación entre la universidad y distintos contingentes sociales, llegando al nivel de la lucha armada, como parte de la época.

En el caso Michoacán, como se desprende de los relatos en un portal de internet, consultado recientemente (La Guerrilla en Michoacán, Amafer Guzmán), en voz propia, señala que, paralelamente a su educación formal, en un ambiente de efervescencia estudiantil asistió a diversos círculos de estudio organizados entre compañeros estudiantes, por la Central Nacional de Estudiantes Democráticos (CNED), por la Juventud Comunista (JC) y por la Casa del Estudiante Nicolaita (CEN), formándose a la par en las luchas estudiantiles y populares. Autodidacta y lector incansable de Marx, Lenin, Mao Tse-Tung, Ernesto Guevara y los clásicos de la literatura socialista, Amafer establece que, antes de ingresar plenamente a la lucha clandestina, se dio a la tarea de desarrollar el Frente Popular Obrero Campesino Estudiantil, con militantes en la Ciénega de Zacapu, la región del Lago de Pátzcuaro, la región Bajío del estado y la capital, entre otros. Luchó al lado de trabajadores de la Celanese de Zacapu, de estudiantes normalistas y universitarios (Tiripetío Michoacán, Mactumactzá Chiapas, Roque Guanajuato, UMSNH) con los Comuneros de Cherán y con colonos de Pátzcuaro, Cuitzeo y Álvaro Obregón por mejoras laborales, servicios públicos, cooperativas comunitarias, reducción de tarifas del transporte público, reducción de precios de la canasta básica de alimentos y tomas y fundación de colonias populares. A la postre, de este Frente Popular, surgirían después diversos militantes que nutrirían las filas del Movimiento de Acción Revolucionaria (MAR). Parte del legado de estas luchas se encuentra en las experiencias más recientes, que van de los años setenta, y aún más en los ochenta en el ámbito del activismo estudiantil michoacano, del cual son parte las casas del estudiante y las agrupaciones que a lo largo de varias décadas se han creado en el ámbito universitario de Michoacán, cuya existencia ha estado ligada en gran medida a la lucha social, fluctuando entre el ámbito comunal, campesino, urbano popular y sindical, diseminados por toda la entidad. 
En lo que corresponde a Nayarit, desde los años setenta, poco después de la creación de la Universidad, y tempranamente surgirían algunas expresiones estudiantiles permeadas por los trágicos sucesos de 68 y 71, marcados por la emergencia de distintos procesos de democratización en las universidades y de movimientos sociales, entre ellos los comunales de Cumbres, las primeras luchas urbanas por parte del Frente de Defensa Popular en la capital, Tepic, el acercamiento a la lucha sindical en la paraestatal Aprovechamientos Forestales de Nayarit (APROFON), la Electrónica Internacional de Nayarit, una empresa transnacional instalada también en la capital y el sindicato del Instituto Mexicano del Café (INMECAFE); un momento en que la vía armada se aprecia como algo factible, por lo que se percibe entre grupos de activistas de la época hubo algunos vínculos que no precisamente llegaron a formas orgánicas, se mantuvieron entre pequeños grupos de distribuidores y lectores interesados del periódico "Madera", principal medio de difusión de la Liga Comunista 23 de Septiembre, en un ambiente en que la universidad se había convertido en un territorio en disputa por parte de los grupos de poder local de arraigo priista, de donde emana el porrismo, el cual se visibilizó a través de distintas organizaciones como la Federación de Estudiantes de la Universidad de Nayarit (FEUN), antecedente de la FEUAN, el Movimiento Organizado, Democrático Universitario (MODU) y la Unidad Liberal Benito Juárez (ULBJ), cada una de las cuales tenía su propio canal de comunicación con el poder local. Confrontados con éstos se fue decantando un movimiento estudiantil que, como se menciona líneas arriba, tempranamente se liga con distintas luchas sociales urbanas, rurales y sindicales, para llegar más tarde a la conformación de un movimiento estudiantil ligado a un sindicalismo democrático, golpeado y reprimido entre 1976 y 1979 , un movimiento de donde surge la máxima expresión de lucha, el Consejo Estudiantil Universitario (CEU), en el marco del gran conflicto de huelga ocurrido entre 1978 y 1979, que marcaría el tránsito hacia un modelo de universidad tradicional y la cancelación de las distintas posibilidades de democratización.

Y finalmente, los casos de Colima y Baja California Sur, donde las cosas no han sido muy claras, que no fueron impactadas, y aún ahora lo que aparece de pronto son expresiones que se enmarcan como acciones colectivas que parten de un contexto en que surgen distintas demandas de nueva generación: derechos humanos, juventud, género, ecología y medio ambiente, entre otras, y donde los universitarios empiezan a ser protagonistas, sin que llegue a ser todavía algo de relevancia mayor, contrastando con los casos anteriores.

En ambos casos, en los últimos años han surgido una variedad de expresiones relacionadas con distintas problemáticas. En Baja California sur conflictos relacionados con el campo y lo que en algún momento fue el proceso de transformación propio del poblamiento y reorganización del territorio de la península que ocupa la entidad. Por los años setenta apareció el Grupo de Acción Popular (GAP), como expresión orgánica de las demandas sociales de distintos sectores, que con los años va tributando en el 
campo electoral al relacionarse y mutar finalmente en el Partido Revolucionario de los Trabajadores (PRT).

En tanto Colima se muestra como un caso en que los movimientos sociales son algo relativamente nuevo, lo que ha estado emergiendo en los últimos años, principalmente en el presente siglo. Colima ha figurado, o al menos durante los últimos veinte años del siglo pasado figuró, como un estado al que se le inyectaron grandes volúmenes de recursos de parte del gobierno federal. Su economía, su educación, teniendo como su referente principal a la Universidad pública; con ello también figuraba en la órbita de los grupos de poder económico y político, ha sido un importante bastión del otrora partido hegemónico, el Partido Revolucionario Institucional (PRI) ${ }^{6}$, como se confirma con la revisión de Rivas Mira (1988) respecto a la sociedad, la economía, la política y la cultura en esta entidad. Con la crisis económica de lago aliento que vivimos en el país y la región, sus efectos en los distintos renglones, entre ellos el educativo, la universidad ha sido el catalizador y en las últimas dos décadas se ha convertido en el escenario en que las disputas sindicales han derivado en importantes rupturas al interior. Además, desde la universidad se han desplegado esfuerzos vinculados a distintas problemáticas: los estudiantes en defensa de la economía familiar a través de las protestas en contra de los aumentos al servicio de transporte urbano; la defensa del territorio y los recursos naturales, como ocurre en el caso de la comunidad Zacualpan o la generación de las condiciones de mayor igualdad social a través del movimiento feminista, ligado también en algún sentido a la dinámica cultural que ha experimentado el estado durante los últimos cincuenta años.

Cabe precisar que en la mayoría de los casos se han dado en forma reciente distintas expresiones y luchas que podrían identificarse como de nueva generación: derechos humanos, juveniles, feministas y ecológicos entre otros. Estos se han tornado en temas transversales para las universidades y han concitado una amplia concurrencia, además de propiciar importantes cambios curriculares en algunos casos, tal cual ocurre en el tema ecológico, que les acerca a otras experiencias en distintos confines en la generación de espacios de formación y educación semejantes (Álvarez y otros, 2021), como elementos potenciadores de la formación académica en la perspectiva de universidad con vocación social y desarrollo regional sustentable y compromiso con entorno. La lucha social se ha tornado variada, cambiante conforme a las circunstancias históricas y en ello la universidad y en general la educación superior han sido un importante catalizador a los largo de varias décadas, de los setenta hacia acá.

\footnotetext{
${ }^{6}$ A lo largo de la historia de la Universidad de Colima ha sido tanta la influencia que ha tenido este partido al punto que se conformó un grupo político compacto, influyente en todos los niveles y ámbitos de la vida colimense, reconocido como el "Grupo Universidad", por el que pasaban y siguen pasando muchas de las decisiones que tienen que ver con la institución y la política local.
} 


\section{CONCLUSIONES}

Cabe destacar que la región objeto de estudio se caracteriza por su conformación diversa en cuanto a la presencia y fuerza de distintas expresiones sociopolíticas, entre las organizaciones y movilizaciones campesinas en la lucha por precios de garantía en los años setenta y ochenta, el movimiento urbano popular, el movimientos magisterial hasta la conformación de núcleos guerrilleros en Sinaloa, Sonora, Jalisco y Michoacán, hasta la presencia de los grupos de autodefensas en Michoacán; de hecho, se trata de una de las regiones con una conformación más plural en ese aspecto, variada en términos sociales y políticos, lo que explica en parte la presencia de más o menos experiencias en este campo de la acción.

Las entidades que la conforman tienen gran experiencia, a excepción de Colima, con la alternancia en cuanto a la fuerza política electoral dominante; existe fuerte presencia del movimiento estudiantil, tanto en la vertiente universitaria, como el de las normales -rurales la mayoría-, y que hasta la fecha, mantienen una fuerte confrontación con el Estado-, el movimiento sindical y el campesino.

Ahora bien, habría que señalar que la política de privatizaciones y la retirada del Estado de la provisión de servicios públicos, al menos de mediana calidad, tuvo fuertes impactos también en las universidades. La constante caída en los ingresos de los profesores, junto a la exigencia de llevar a cabo un creciente número de actividades, relacionados con la llamada gestión académica-administrativa, tuvo al menos dos consecuencias: la búsqueda de un segundo empleo y una merma en la calidad de su función como formadores/impulsores de un pensamiento crítico en los estudiantes, con un mínimo de compromiso social. Sumariamos, el efecto a nivel social, del discurso individualista, que nos hace responsables de alcanzar el éxito de la sociedad posmoderna, sin tomar en cuenta al resto de la sociedad. Valores como solidaridad, justicia social, democracia, se han desvanecido. Tal vez esto nos permita entender el poco peso que los movimientos sociales alcanzan hoy en día; aunado a su fragmentación manifiesta. Movimientos feministas con posturas radicales que más que sumar parecen restar solidaridad, al plantear extremos, buenos y malos. Grupos indígenas abandonados a su suerte, dada la incapacidad de la sociedad para entender y asimilar la diversidad cultural y lingüística de nuestra región y país.

De cualquier manera, la educación superior como un bien común en las sociedades contemporáneas, a contracorriente de los propósitos del Estado como principal gestor y dador, se ha convertido en un amplio referente para los distintos grupos sociales, principalmente porque desde el ámbito estudiantil, magisterial o sindical se vienen construyendo vasos comunicantes muy importantes al grado que las distintas expresiones orgánicas en cada uno de esos ámbitos se han sido muchas de las veces las correas de transmisión que acercan a la sociedad con la vida pública en todos los niveles. En ese sentido, la universidad pública, las escuelas normales, las agrupaciones estudiantiles y los sindicatos han 
sido para la sociedad en las distintas regiones, presencias valiosas en la lucha por mejor condiciones de vida y la democratización de la vida política. 


\section{BIBLIOGRAFÍA}

Alvarez, J. y otros, 2021, "Trabajando la educación ambiental desde la metodología aprendizaje-servicio", en South Florida Journal of Development, Miami, v.2, n.1 jan./feb, pp. 105-118.

Borja, J., 1981, "Movimientos urbanos y cambio político", en Revista Mexicana de Sociología. IISHUNAM. México, pp. 1341- 1369.

Argentina.

1974, Movimientos Sociales Urbanos. Ed. SIAP, Buenos Aires,

Castells, M., 1983, Movimientos Sociales Urbanos. S. XXI eds., México.

----------, 1983, La ciudad y las masas: Sociología de los movimientos sociales urbanos. Alianza Universidad (Textos), Madrid, España.

Castellanos, L. y A. Jiménez, 2007, México armado. Ediciones Era, México, pp. 383.

Galindo, L. J., 1987, Movimiento Social y Cultura Politica. Discurso, conciencia, historia... Universidad de Colima, México.

Guevara, G., 1988, La democracia en la calle. Crónica del movimiento estudiantil mexicano. Siglo XXI Editores, México.

León, S. e I. Marván, 1989, "Los movimientos sociales en México (1968-1983). Panorama general y perspectivas", en CAMACHO, Daniel y Rafael Menjívar (coords.). Movimientos populares en América Latina. S.XXI eds., México.

Link, T. A. (1985), "Sistemas de producción y región”, en Alcántara Ferrer, Sergio y Enrique Sánchez Ruiz (Comps.), Desarrollo rural en Jalisco: Contradicciones y perspectivas. El Colegio de Jalisco/CONACYT, Guadalajara, Jal. México.

Mejía, M. y S. Sarmiento, 1987, La lucha indígena: un reto a la ortodoxia, S. XXI eds., México.

Moctezuma, P. y B. Navarro, 1984, "Proletariado, Estado y reproducción de la fuerza de trabajo en colonias populares”, en Nueva Antropología No. 24, vol. VI, México, pp. 5-19

Navarro, B., 1983, "MUP y acumulación de capital en México", en Testimonios No. 1. Universidad Autónoma de Guerrero, México, pp. 69-75.

Nuñez, O., 1990, ¿Masas o asociaciones en el origen del movimiento urbano popular?”, en Sociología. UAM-A, México, pp. 129-149.

Perló, M. y M. Schteigart, 1984, "Movimientos sociales urbanos en México", en Revista Mexicana de Sociología. IISH-UNAM, México, pp. 105-125.

Ramírez, J. M., 1984, "Movimientos sociales urbanos en México: elementos para una nueva caracterización”, en Nueva antropología. No. 24, vol. IV, México, pp. 21-50. 
Oikion, V., "La guerrilla olvidada. La historia de una página manchada con sangre de estudiantes de la Universidad de Guadalajara", en Letras Históricas / Número 13 / Otoño 2015-invierno 2016 / México / pp. 255-260.

Rivas, F., 1988, Colima. Sociedad, economía, política y cultura. CIISH-UNAM, México

Sánchez Parra, S., 2006, "La guerrilla en México: un intento de balance historiográfico”, en Clío, Nueva Época, vol. 6, núm. 35.

Tamayo, S., 2009, "Participación ciudadana y movimientos sociales", en Mestres, F., G. Pleyers y S. Zermeño (Coords.), Los movimientos sociales de lo local a lo global. Ed. Anthropos/UAM-A, México, pp. 79-103.

Tilly, Charles y L. J. Wood, 2009, Los movimientos sociales, 1768-2008. Desde sus orígenes a Facebook. Ed. Crítica, Barcelona.

Touraine, Alain, 1982, "Reacciones antinucleares o movimiento antinuclear", en Revista Mexicana de Sociología. IIS-UNAM. México, pp. 689-701.

1986, "Los movimientos sociales", en GALVAN, F., Touraine y Habermas: ensayos de teoría social. UAP-UAM/A, México.

Van Young, E. (1992), “Introduction: Are Regions good to Think?”, en Van Young, Eric (Ed), Mexico's Regions. Center for U.S.-Mexican Studies. USCD

Verdugo, J., 2004, "El movimiento estudiantil en la Universidad de Sonora de 1970 a 1974 . Un enfoque sociohistórico a partir del testimonio oral", Hermosillo, Sonora, Serie Cuadernos Cuarto Creciente no. 9 El Colegio de Sonora, pp. 248.

Tomado de: http://pavelulianov.blogspot.mx/2011/01/la-guerrilla-en-michoacan.html, consultado el 13 de septiembre de 2017. 